\title{
PENGGANTIAN NAZHIR WAKAF PERSEORANGAN KE BADAN HUKUM DALAM PERSPEKTIF MAQASHID ASY-SYARI'AH (Studi di Badan Wakaf Indonesia Perwakilan Kota Tasikmalaya)
}

\author{
Acep Zoni Saeful Mubarok \\ Program Studi Ekonomi Syari’ah, Universitas Siliwangi, accefs@unsil.ac.id
}

\begin{abstract}
The study aims at examining how the replacement of Nazaf waqf from individual Nazar to legal entity Nazar in the perspective of Maqashid ash-Shari'ah. The method used is normative research containing empirical elements with a qualitative approach. Source of data comes from reference data (library) and the results of field studies and interviews with various parties (fields) located in the City of Tasikmalaya. The results of this study are the replacement of individual nazhir to legal body referring to the public benefit, namely the control of waqf assets owned by the legal body. Besides, it constitutes the spirit to realize the objectives of maqashid asy-syari'ah waqf itself. From the perspective of maqashid al-shari'ah, the replacement of waqf from individuals to legal body is to realize the objectives of waqf in accordance with Shari'a (hifz ad-din), improve the professionalism of Nazir persons (hifdz annafs), perpetuate the benefits of waqf and improve the economy (hifz al-mal).
\end{abstract}

Keywords : nazhir, waqf, maqashid al-shari'ah

\begin{abstract}
ABSTRAK
Studi ini bertujuan untuk mengkaji bagaimana penggantian nazhir wakaf dari nazhir perseorangan ke nazhir badan hukum dalam perspektif maqashid asy-syari'ah. Metode yang digunakan dalam studi ini adalah penelitian normatif yang mengandung elemen empiris dengan pendekatan kualitatif. Sumber data berasal dari data referensi (library) dan hasil studi lapangan serta wawancara dengan berbagai pihak (field) yang berlokasi di Kota Tasikmalaya. Hasil studi ini adalah penggantian nazhir perseorangan kepada badan hukum mengacu kepada kemaslahatan umum yaitu penertiban aset wakaf yang dimiliki oleh badan hukum itu sendiri selain hal itu merupakan semangat untuk mewujudkan tujuan maqashid asy-syari'ah wakaf itu sendiri. Dari perspektif maqashid asy-syari'ah, penggantian nazhir wakaf dari perseorangan ke badan hukum adalah untuk mewujudkan tujuan wakaf sesuai syariat (hifz ad-din), meningkatkan profesionalitas person nazhir (hifz an-nafs), dan mengabadikan manfaat wakaf dan meningkatkan perekonomian (hifz al-mal).
\end{abstract}

Kata Kunci: nazhir, wakaf, maqashid al-syari'ah 


\section{PENDAHULUAN}

Wakaf merupakan pranata hukum Islam yang legalitasnya didasarkan pada al-Quran dan hadits. Selain itu, pengambilan hukum berkenaan dengan wakaf juga bersumber dari ijtihad yang menitikberatkan pada segi maqashid asy-syari'ah, yaitu mewujudkan kemaslahatan dan menjauhkan kemadaratan (Fikfik Taufik, 2014). Dalam pengelolaannya wakaf diatur oleh aturan syar'i yang secara tegas dibimbing oleh al-Qur'an dan hadits. Disamping itu dalam regulasi hukum nasional, penyelenggaraan wakaf diatur pula dalam perundang-undangan dan peraturan lainnya. Ini membuktikan bahwa wakaf memiliki potensi yang luar biasa yang perlu mendapatkan perhatian secara legal formal.

Pelaksanaan wakaf sesunggunya sangatlah mudah, apabila terpenuhi unsur-unsurnya maka jadilah wakaf itu. Unsur-unsur wakaf tersebut sebagaimana disebutkan pada pasal 6 Undang-undang No 41 Tahun 2004 tentang wakaf bahwa wakaf dilaksanakan dengan memenuhi unsur wakaf sebagai berikut: a. Wakif; b. Nazhir; c. Harta Benda Wakaf; d. Ikrar Wakaf; e. peruntukan harta benda wakaf; f. jangka waktu wakaf (Tim Penulis BWI, 2018).

Unsur-unsur yang tertuang dalam peraturan ini, terdapat salah satu unsur yang dianggap memiliki peran penting yaitu nazhir (Direktorat Pengembangan Zakat dan wakaf, 2004). Nazhir wakaf memiliki peran yang sangat urgen dan strategis dalam perwakafan, karena bertugas untuk mengelola harta wakaf dengan sebaik-baiknya. Realitas yang ada di masyarakat, peran nazhir masih kurang maksimal dalam menjalankan tugas menjaga, mengelola dan mengembangkan tanah wakaf.

Hasil penelitian Pusat Bahasa dan Budaya (PBB) UIN Syarif Hidayatullah Jakarta kepada 500 responden nazhir di 11 Provinsi, harta wakaf lebih banyak bersifat diam (77\%) daripada yang menghasilkan atau produktif (23\%). Termasuk wakaf lebih banyak dikelola oleh perseorangan $(66 \%)$ alias tradisional, daripada organisasi professional (16\%) dan berbadan hukum (18\%) (Abdurrahman Kasdi, 2014).

Beberapa badan hukum baik ormas Islam atau yayasan berusaha mengoptimalkan tugas nazhir. Salah satu ikhtiar tersebut adalah dengan cara melakukan penggantian nazhir wakaf, dari nazhir perseorangan menjadi nazhir lembaga berbadan hukum. Penggantian nazhir ke badan hukum ini merupakan hal yang baru tapi dilindungi oleh negara. Tujuan dari perubahan nazhir wakaf ini tiada lain sebagai salah satu usaha optimalisasi pengelolaan harta wakaf supaya lestari, bersifat abadi, dan memiliki nilai-nilai kemaslahatan yang lebih luas untuk umat sesuai dengan tujuan syariat Islam (maqashid asy-syari'ah) itu sendiri.

Berdasarkan BPS Kota Tasikmalaya sebagai Kota Santri memiliki penduduk mayoritas beragama Islam sebanyak 628,018 jiwa tentu sudah sangat paham dan sangat akrab dengan perwakafan. Potensi wakaf di Kota Tasikmalaya tersebar di 1.679 lokasi seluas 81,20 Ha. Jumlah ini merupakan potensi yang sangat luar biasa apabila diberdayakan dengan baik dan optimal.

Untuk kasus di Kota Tasikmalaya ada beberapa badan hukum yang berusaha mengalihkan nazhir supaya lebih optimal dan lebih maslahat. Dalam kurun waktu tahun 2018 telah terjadi penggantian nazhir wakaf yang sangat masif di Kota Tasikmalaya. Menurut data 
Badan wakaf Indonesia (BWI) Perwakilan Kota Tasikmalaya ada 15 lokasi yang mengajukan penggantian nazhir dari perseorangan menjadi badan hukum. Menurut Ketua BWI Kota Tasikmalaya, hal ini didorong oleh beberapa faktor diantaranya instruksi dari induk lembaga badan hukum itu sendiri dan yang lebiih utamanya adalah untuk lebih kepada faktor keamananan aset dan kemaslahatan yang lebih jauh dibanding nazhir wakaf perseorangan (M. Djayadi, 2016).

Studi ini akan melihat sejauh mana penggantian nazhir wakaf perseorangan ke badan hukum di wilayah hukum Badan Wakaf Indonesia (BWI) Perwakilan Kota Tasikmalaya. Kemudian bagaimana penggantian nazhir wakaf ke badan hukum dalam perspektif maqashid syariah, apakah mengandung nilai-nilai yang lebih mashlahah dibandingkan dengan nazhir perseorangan.

\section{LITERATUR REVIEW Nazhir Wakaf}

Nazhir memiliki kedudukan yang urgen dan signifikan dalam wakaf. Eksistensi dan pemberdayaan wakaf sangat tergantung pada nazhir dalam menjaga dan mengelola harta wakaf. Kajian para ulama yang tersaji dalam kitab-kitab fiqh serta regulasi wakaf di Indonesia yang tertuang dalam Undang-undang No 41 Tahun 2004 tentang wakaf, dengan secara rinci dan gamblang mengatur persoalan nazhir tersebut.

Pengertian nazhir secara bahasa berasal dari kata nazara yang berarti ra'a (melihat) abshara (memandang) dan tadabbara (merenungkan, memikirkan, mempertimbangkan) (Ahmad Warson Munawwir, 1984). Secara istilah dapat merujuk kepada pasal 1 ayat 4 Undang-undang No 41 Tahun 2004 tentang wakaf disebutkan nazhir adalah pihak yang menerima harta benda wakaf dari Wakif untuk dikelola dan dikembangkan sesuai dengan peruntukannya (Tim BWI, 2018). Adapun yang menjadi tugas Nazhir adalah: a.melakukan pengadministrasian harta benda wakaf; b. mengelola dan mengembangkan harta benda wakaf sesuai dengan tujuan, fungsi, dan peruntukannya; c. mengawasi dan melindungi harta benda wakaf; d. melaporkan pelaksanaan tugas kepada Badan Wakaf Indonesia.

Dalam Undang-undang tersebut diatur bahwa nazhir itu terdiri dari nazhir perorangan, organisasi atau badan hukum. Syarat-syarat untuk nazhir perseorangan adalah warga negara Indonesia, Islam, dewasa, amanah, mampu secara jasmani dan rohani serta tidak terhalang melakukan perbuatan hukum. Untuk nazhir organisasi harus memenuhi persyaratan: (1) pengurus organisasi yang bersangkutan memenuhi syarat-syarat nazhir perorangan. (2) organisasi tersebut bergerak di bidang sosial, pendidikan, kemasyarakatan dan atau keagamaan Islam. Sedangkan nazhir badan hukum memiliki syarat sebagai berikut: (1) pengurus Badan Hukum yang bersangkutan memenuhi syarat-syarat nazhir perorangan. (2) Badan Hukum Indonesia yang dibentuk sesuai dengan peraturan perundang-undangan yang berlaku. (3) Badan Hukum yang bersangkutan bergerak di bidang sosial, pendidikan, kemasyarakatan dan atau keagamaan Islam. 


\section{Peran Badan Wakaf Indonesia (BWI)}

BWI dibentuk bukan untuk mengambil alih aset-aset wakaf yang selama ini dikelola oleh nazhir (pengelola aset wakaf) yang sudah ada. BWI hadir untuk membina nazhir agar aset wakaf dikelola lebih baik dan lebih produktif sehingga bisa memberikan manfaat lebih besar kepada masyarakat, baik dalam bentuk pelayanan sosial, pemberdayaan ekonomi, maupun pembangunan infrastruktur publik.

Adapun tugas dan wewenang BWI berdasarkan Pasal 49 Ayat 1 Undang-Undang Nomor 41 Tahun 2004 tentang Wakaf, adalah sebagai berikut:

1. Melakukan pembinaan terhadap nazhir dalam mengelola dan mengembangkan harta benda wakaf.

2. Melakukan pengelolaan dan pengembangan harta benda wakaf berskala nasional dan internasional.

3. Memberikan persetujuan dan atau izin atas perubahan peruntukan dan status harta benda wakaf.

4. Memberhentikan dan mengganti nazhir.

5. Memberikan persetujuan atas penukaran harta benda wakaf.

6. Memberikan saran dan pertimbangan kepada Pemerintah dalam penyusunan kebijakan di bidang perwakafan.

Salah satu tugas Badan wakaf Indonesia sebagaimana dipaparkan di atas adalah memberhentikan dan mengganti nazhir. Dalam penggantian nazhir ini ada peraturan yang secara khusus menjelaskan hal itu yaitu Peraturan Badan Wakaf Indonesia.

\section{Tugas dan Wewenang BWI dalam Penggantian Nazhir}

Dalam Pasal 5 ayat (1) Perwakilan BWI Provinsi memiliki tugas dan wewenang sebagai berikut: 1. Melaksanakan kebijakan dan tugas-tugas BWI di tingkat Provinsi; 2. Melakukan koordinasi dengan kanwil kemenag dan instansi terkait dalam rangka pelaksanaan tugas BWI Provinsi; 3. Melakukan pembinaan terhadap Nazhir dalam mengelola dan mengembangkan harta benda wakaf; 4. Bertindak dan bertanggung jawab untuk dan atas nama Perwakilan BWI Provinsi baik ke dalam maupun ke luar; 5. Memberhentikan dan/atau mengganti Nazhir yang luas tanah wakafnya $1000 \mathrm{M}^{2}$ (seribu meter per segi) sampai dengan $20.000 \mathrm{~m}^{2}$ (dua puluh ribu meter persegi); 6. Menerbitkan tanda bukti Pendaftaran Nazhir yang luas tanah wakafnya $1000 \mathrm{~m} 2$ sampai dengan $20.000 \mathrm{~m}^{2}$ (dua puluh ribu meter persegi); 7. Melaksanakan survey dan membuat laporan atas usul perubahan peruntukan harta benda wakaf yang luasnya paling sedikit $1000 \mathrm{M}^{2}$ (seribu meter per segi); 8. Melaksanakan survey dan membuat laporan atas usul penukaran/perubahan status harta benda wakaf (ruislagh) berupa tanah yang luasnya paling sedikit $1000 \mathrm{M}^{2}$ (seribu meter per segi); 9. Melaksanakan tugas-tugas lain yang diberikan oleh BWI.

Ayat (2) Perwakilan BWI Kabupaten/Kota memiliki tugas dan wewenang untuk: 1. Melaksanakan kebijakan dan tugas-tugas BWI di tingkat kabupaten/kota; 2. Melakukan 
koordinasi dengan kankemenag dan instansi terkait dalam rangka pelaksanaan tugas BWI kabupaten/kota; 3. Melakukan pembinaan terhadap nazhir dalam mengelola dan mengembangkan harta benda wakaf; 4. Bertindak untuk dan bertanggung jawab untuk dan atas nama Perwakilan BWI kabupaten/kota baik ke dalam maupun ke luar; 5 . Memberhentikan dan mengganti Nazhir yang luas tanah wakafnya kurang dari $1000 \mathrm{M}^{2}$ (seribu meter per segi); 6. Menerbitkan tanda bukti Pendaftaran Nazhir yang luas tanah wakafnya kurang dari 1000M2 (seribu meter per segi); 7. Melaksanakan survey dan membuat laporan atas usul perubahan peruntukan harta benda wakaf berupa tanah yang luasnya kurang dari $1000 \mathrm{M}^{2}$ (seribu meter per segi); 8. Melaksanakan survey dan membuat laporan atas usul penukaran/perubahan status harta benda wakaf (ruislagh) berupa tanah yang luasnya kurang dari $1000 \mathrm{M}^{2}$ (seribu meter per segi); 9. Melaksanakan tugas-tugas lain yang diberikan oleh Perwakilan BWI Provinsi.

Dalam aturan ini secara jelas disebutkan bahwa penggantian nazhir wakaf merupakan kewenangan Badan wakaf Indonesia. Untuk perwakilan Kota/kabupaten penggantian Nazhir hanya bagi yang memiliki luas tanah wakafnya kurang dari $1000 \mathrm{M}^{2}$ (seribu meter per segi), sedangkan lebih dari itu merupakan kewengan Provinsi.

\section{Maqashid asy-Syari'ah}

Maqashid asy-Syari'ah merupakan merupakan kata idlafî (majemuk) yang terdiri dari dua kata yaitu Maqâshid dan asy-Syarî‘ah. Dari segi bahasa kata maqashid merupakan bentuk plural atau jamak dari kata maqshid yang memiliki arti tuntutan, kesengajaan atau tujuan (Hans Wehr, 1980). Sedangkan syari'ah bahasa adalah "jalan menuju air" (Ibn Manzur alAfriqi, $t \mathrm{t}$ ). Sedangkan syari’ah dalam literatur hukum Islam mempunyai tiga pengertian: pertama, syari ah dalam arti sumber hukum yang tidak dapat berubah sepanjang masa. Kedua, syari ah dalam pengertian sumber hukum Islam yang dapat berubah. Ketiga, syari`ah dalam pengertian hukum ketentuan yang digali dari al-Qur`an san sunnah (Juhaya S. Praja, 1995).

Adapun pengertian maqasid asy-syari'ah adalah tujuan yang dikehendaki syara' dan rahasia-rahasia yang ditetapkan oleh syari' (Allah) pada setiap hukum (Allal al-Fasi, 1971). Dengan kata lain maqasid asy-syari'ah merupakan tujuan Allah sebagai syari' (Pembuat Hukum) dalam menetapkan hukum terhadap hamba-Nya. Inti dari maqasid asy-syari'ah, untuk mewujudkan kebaikan sekaligus menghindarkan keburukan, atau menarik manfaat, menolak mudharat (Amir Muâllim dan Yusdani, 1999), mencapai kemaslahatan dalam rangka memelihara tujuan-tujuan syara (Abu Hamid al-Gazali, 1983).

Menurut asy-Syatibi (Ibn Yusuf al Juwaini, tt; Abu Hamid al-Gazali, 1999) memahami maqasid asy-syari'ah sangat penting dilakukan saat ulama mujtahid akan melakukan istinbath hukum. Karena dengan memahami maqasid asy-syari'ah akan dapat diketahui tujuan Allah dalam menetapkan hukumNya. Untuk itulah asy-Syatibi menekankan apabila upaya penggalian hukum syara' itu berhasil secara optimal maka seorang ulama mujtahid itu harus mampu memahami maqasid asy-syari'ah (ash-Shatibi, 1975). 
Lebih lanjut Al-Ghazali menyatakan bahwa inti dari maqasid asy-syari'ah adalah untuk mencapai kemaslahatan, karena tujuan penetapan hukum dalam Islam adalah untuk menciptakan kemaslahatan dalam rangka memelihara tujuan-tujuan syara. Adapun tujuan syara yang harus dipelihara itu adalah menjaga agama, menjaga jiwa, menjaga akal, menjaga keturunan dan menjaga harta (Abu Hamid al-Gazali, 1999).

\section{Maṣlaḥah sebagai Inti Maqashid}

Inti maqāṣid asy-Syari'ah adalah maṣlaḥah. Dengan maṣlaḥah inilah persoalanpersoalan kontemporer yang sebelumnya belum hadir dalam khazanah hukum Islam klasik mampu dijawab dan didekati. Maṣlaḥah secara etimologis dapat berarti kebaikan (Ahmad Warson Munawwir, 1984), kemanfaatan (benefit) (Dale F. Eickelman, 2000), kepantasan, kelayakan, keselarasan, kepatutan. Kata Mașlaḥah dilawankan dengan kata mafsadah (Muhammad ibn Ya'qub al-Fairuz Abadi, tt) dan adakalanya dilawankan dengan kata madharrah yang mengandung arti kerusakan.

Ash-Shatibi mengemukakan bahwa mașlaḥah merupakan sesuatu yang dipahami untuk memeliharanya sebagai suatu hak hamba, dalam bentuk meraih kemaslahatan dan menolak kemafsadatan yang untuk mengetahuinya tidak didasarkan ada akal semata. Jika Allah SWT tidak memberikan penegasan terhadapnya bahkan menolaknya, maka kaum muslimin sepakat menolaknya sebagai kemaslahatan" (asy-Syatibi, tt)

Sementara Al-Gazali (w. 505 H/1111 M) berpendapat bahwa makna dasar dari mașlaḥah adalah mewujudkan kemanfaatan (jalb al-manfa 'ah) atau menghindari kemudaratan (daf'u al-madharrah). Lebih jauh al-Gazâli, menyebutkan bahwa maslahah, dalam arti terminologis shar'i adalah memelihara dan mewujudkan shari'ah berupa memelihara agama, jiwa, akal, keturunan, dan harta (Abu Hamid al-Gazali, 1999). Menjurut al-Gazâli bahwa setiap sesuatu yang dapat melindungi eksistensi salah satu dari kelima hal tersebut dikualifikasi sebagai mașlahah, tetapi setiap sesuatu yang dapat mengganggu dan mengabaikan salah satu dari kelima hal tersebut dinilai sebagai mafsadah serta menolak terhadap sesuatu yang mengabaikannya merupakan mașlaḥah (Abu Hamid al-Gazali, 1999).

\section{Jenis-jenis Maṣlahah}

Jenis dan ragam mașlahah dapat dipilah dan diklasifikasi menurut beberapa sudut pandang (Abu Yasid, 2011). Berikut ini paparan beberapa sudut pandang tersebut:

Ditinjau dari segi otoritas shari' (pembuat syari'ah) para ulama membagi mașlaḥah kepada tiga kategori, yaitu: Pertama, Maṣlaḥah yang keberadaannya diakui oleh dalil syara' secara tersura atau yang dikenal dengan maṣlahah mu'tabarah (Robert Dickson Crane, $t \mathrm{t}$ ). Seperti terjadinya pengharaman segala bentuk minuman memabukkan dengan diqiyaskan pada minuman arak (khamr) yang telah disebutkan teks pengharamannya oleh AlQur'an. Kedua, Mașlaḥah yang keberadaannya tidak diakui shara' secara tersurat. Maṣlaḥah ini tidak dapat dijadikan sumber hukum karena bertentangan dengan nash (Abu Hamid alGazali, 1999) Maṣlaḥah ini dikenal dengan mașlaḥah mulgah (Issa Qaed and Elvan Syaputra, 
2014). Jenis mașlaḥah ini biasanya berhadapan secara kontradiktif dengan bunyi teks Alqur'an maupun Hadis. Ketiga, Mașlaḥah al-Mursalah yaitu mașlahah yang tidak terdapat dalil shara' yang mengakuinya maupun yang menolaknya dalam bentuk nash tertentu (Abu Hamid al-Gazali, 1999).

Ditinjau dari segi kualitas, sebagaimana para ulama sepakat bahwa Allah SWT menetapkan ketentuan syari'at dengan tujuan untuk memelihara lima perkara sebagai maqashid asy-syari'ah atau menurut istilah Al-Ghazali adalah al-usul al-khamsah atau al-usul al-shari'ah atau ad-daruriyyat al-khamsah yaitu memelihara agama, jiwa, akal, keturunan dan harta (Said Agil Husin Al-Munawar, 1997). Untuk memelihara dan menjaga tujuan syariat ini para ulama membagi kepada tiga kategori tingkatan maṣlaḩah ditinjau dari segi kualitas yaitu:

Pertama, Al-Mașlaḥah ad-Daruriyyat (kemaslahatan primer). Kemaslahatan ini merupakan sesuatu yang mutlak dan harus ada untuk mewujudkan kebaikan di dunia maupun akhirat. Kedua, Al-Mașlaḥah al-Hajiyyat (kemaslahatan sekunder). Mașlahah ini bersifat sekunder, bilamana tidak terwujud tidak sampai mengancam keselamatannya, namun akan mengalami kesulitan. Mașlaḥah yang dibutuhkan untuk kelapangan dan menghilangkan kesempitan. Ketiga Al-Maslahah al-Tahsiniyat (kemaslahatan tersier). Al-Mașlaḥah tingkat tersier ini adalah sesuatu yang sebaiknya ada untuk memperindah kehidupan bilamana $\mathrm{Al}$ Maṣlaḥah ini diabaikan maka akan menyebabakan runtuhnya etika moral dalam kehidupan beragama. Keberadaannya dikehendaki untuk kemuliaan akhlak dan kebaikan tatatertib pergaulan. Contoh mașlahah jenis ini bisa kita lihat dalam beragam kehidupan ritual maupun sosial keagamaan (Amir Syarifuddin, 2011).

Majelis Ulama Indonesia menetapkan ukuran yang lebih konkret mengenai kemaslahahan ini sebagaimana tertuang dalam putusan Musyawarah Nasional ke VII Tahun 2005. Dalam putusan MUI No. 6/MUNAS/VII/MUI/10/2005 Majelis Ulama Indonesia memberikan kriteria maslahah sebagai berikut:

Pertama, Kemaslahatan menurut hukum Islam adalah tercapainya tujuan syariah (maqasid al-Shari'ah) yang diwujudkan dalam bentuk terpeliharanya lima kebutuhan primer (ad-Daruriyyah al-Khamsah), yaitu agama, jiwa, akal, harta, dan keturunan. Kedua, Kemaslahatan yang dibenarkan oleh syariat adalah kemaslahatan yang tidak bertentangan dengan nas. Ketiga, Yang berhak menentukan mașlahah dan tidaknya sesuatu menurut syariah adalah lembaga yang mempunyai kompetensi di bidang syariah dan dilakukan melalui ijtihad jama'i.

Untuk mencapai kemaslahatan dalam menghadapi persoalan hukum kontemporer dapat didekati setidaknya dengan menggunakan analisis al-usul al-khamsah atau al-usul alshari'ah atau ad-daruriyyat al-khamsah yaitu: (1) memelihara agama (hịiz al-dīn), (2) memelihara jiwa (hifz al-nafs), (3) memelihara akal pikiran (hifz al-'aql), (4) memelihara keturunan (hifz al-nasl), dan (5) memelihara harta kekayaan (hifẓ al-māl) menjadi alat ukur dalam enilai kemaslahatan pada perubahan ststus Nazdir wakaf dari perseorangan ke badan hukum. 


\section{METODE}

Penelitian ini merupakan penelitian normatif yang mengandung elemen empiris dengan pendekatan kualitatif. Sumber data primer dalam studi ini adalah data-data dari BWI Kota Tasikmalaya dan wawancara terhadap pengurus Badan Wakaf Indonesia (BWI) Kota Tasikmalaya dan pelaku penggantian nazhir wakaf yang dilakukan untuk mengetahui sejauh mana penggantian nazhir wakaf dari perseorangan ke badan hukum mengandung nilai-nilai maslahah yang merupakan inti maqashid asy-syari'ah. Wawancara dilakukan kepada 3 (tiga) orang yang mewakili badan hukum tersebut yaitu: KH. Arip Somantri, M.Ag. (Sekretaris PD Muhammadiyah Kota Tasikmalaya, Ust. Surya (Ketua Bidgar Perwakafan PD Persis Kota Tasikmalaya, dan Ust Imam Muharram (Pengelola wakaf Yayasan Idrisiyyah Kec Tawang).

Teknik pengumpulan data dalam penelitian ini menggunakan teknik pengumpulan data yang menggabungkan berbagai teknik pengumpulan data dan sumber data yang telah ada. Dalam penelitian ini dilakukan pengumpulan data berupa data-data dari BWI Kota Tasikmalaya dan Kantor kementerian Agama Kota Tasikmalaya baik secara tertulis maupun wawancara.

Adapun teknik analisis data pada penelitian ini merupakan teknik analisis dengan pendekatan Maqashid Syariah. Penelitian ini menggunakan analisis deskriptif agar dapat diinterpretasikan dan mudah dipahami dengan berpatokan pada nilai-nilai kemaslahatan dengan analisis al-usul al-khamsah atau al-usul al-syari'ah atau ad-daruriyyat al-khamsah yaitu: (1) memelihara agama (hịz al-dīn), (2) memelihara jiwa (hifẓ al-nafs), (3) memelihara akal pikiran (hifẓ al-'aql), (4) memelihara keturunan (hifz al-nasl), dan (5) memelihara harta kekayaan (hị al al-māl) yang menjadi alat ukur dalam menilai kemaslahatan pada penggantian nazhir wakaf dari perseorangan ke badan hukum.

\section{HASIL DAN PEMBAHASAN}

\section{BWI dan Perwakafan di Kota Tasikmalaya}

Kota Tasikmalaya memiliki potensi wakaf yang cukup potensial disamping memiliki keanekaragaman persoalan wakaf. Kehadiran Badan Wakaf Indonesia (BWI) Perwakilan Kota Tasikmalaya memberikan angin segar kepada umat Islam di Kota Tasikmalaya karena dapat memberikan kemudahan dalam mengurus masalah perwakafan.

Perjalanan organisasinya BWI Perwakilan Tasikamalaya telah berdiri dan mengemban amanah tugas dimulai sejak masa jabatan pertama yatitu 2016 - 2019 sampai sekarang 2019 2022. BWI Perwakilan Kota Tasikmalaya diamanahi tugas untuk memberikan bimbingan, arahan, dan bantuan supaya wakaf sesuai dengan tujuan dan fungsinya sebagaimana yang diamanahkan oleh Undang-undang wakaf yaitu bertujuan memanfaatkan harta benda wakaf sesuai dengan fungsinya. Amanah yang lainnya yaitu bertugas membimbing agar wakaf dapat berfungsi mewujudkan potensi dan manfaat ekonomis harta benda wakaf untuk kepentingan ibadah dan untuk memajukan kesejahteraan umum. 
BWI Perwakilan Kota Tassikmalaya mengemban amanah membangkitkan potensi wakaf di Kota Tasikmalaya. Provinsi Jawa Barat sebagaimana data dari Sistem Informasi wakaf Kementerian Agama, Jawa Barat memikiki tanah wakaf seluas 4.788,70 Ha, dengan 69.322 lokasi dengan tanah wakaf yang berrsertifikat seluas 2.208,43 Ha, yang tersebar 38.799 lokasi, serta tanah yang belum bersertifikat seluas 2.580,26 Ha yang tersebar 30.523 lokasi.

Jumlah tanah wakaf yang diketahui sebagai tanah wakaf semuanya seluas 81,20 Ha yang tersebar di 1.679 lokasi se- Kota Tasikmalaya dengan perincian tanah wakaf yang sudah bersertifikat semuanya seluas $72,74 \mathrm{Ha}$ yang terdapat di 1.533 lokasi dan yang belum bersertifikat seluas 8,46 Ha tersebar di 146 lokasi. Data jumlah tanah wakaf se-wilayah Provinsi Jawa Barat dapat dilihat dalam tabel 1.

Tabel 1. Data Jumlah Tanah Wakaf di Wilayah Kota Tasikmalaya

\begin{tabular}{|c|c|c|c|c|c|c|c|}
\hline \multirow[b]{2}{*}{ o } & \multirow{2}{*}{$\begin{array}{c}\text { Kantor Urusan } \\
\text { Agama }\end{array}$} & \multirow[b]{2}{*}{ Jumlah } & \multirow{2}{*}{$\begin{array}{l}\text { Luas } \\
{[\mathrm{Ha}]}\end{array}$} & \multicolumn{2}{|c|}{ Sudah Sertifikat } & \multicolumn{2}{|c|}{ Belum Sertifikat } \\
\hline & & & & Jumlah & $\begin{array}{l}\text { Luas } \\
\text { [Ha] }\end{array}$ & Jumlah & $\begin{array}{l}\text { Luas } \\
{[\mathrm{Ha}]}\end{array}$ \\
\hline & Kawalu & $\underline{191}$ & $\underline{10,60}$ & $\underline{73}$ & $\underline{3,70}$ & $\underline{118}$ & $\underline{6,90}$ \\
\hline & Indihiang & $\underline{336}$ & $\underline{23,72}$ & $\underline{335}$ & $\underline{23,69}$ & $\underline{1}$ & $\underline{0,04}$ \\
\hline & Cibeureum & $\underline{171}$ & $\underline{5,45}$ & $\underline{171}$ & $\underline{5,45}$ & $\underline{0}$ & $\underline{0,00}$ \\
\hline & Cipedes & $\underline{64}$ & $\underline{1,09}$ & $\underline{64}$ & $\underline{1,09}$ & $\underline{0}$ & $\underline{0,00}$ \\
\hline & Cihideung & $\underline{230}$ & $\underline{8,51}$ & $\underline{229}$ & $\underline{8,44}$ & $\underline{1}$ & $\underline{0,07}$ \\
\hline & Tawang & $\underline{133}$ & $\underline{3,99}$ & $\underline{128}$ & $\underline{3,84}$ & $\underline{5}$ & $\underline{0,15}$ \\
\hline & Tamansari & $\underline{94}$ & $\underline{2,76}$ & $\underline{87}$ & $\underline{2,41}$ & $\underline{7}$ & $\underline{0,35}$ \\
\hline & Mangkubumi & $\underline{159}$ & $\underline{7,98}$ & $\underline{156}$ & $\underline{7,72}$ & $\underline{3}$ & $\underline{0,26}$ \\
\hline & Purbaratu & 95 & $\underline{3,66}$ & $\underline{87}$ & $\underline{3,02}$ & $\underline{8}$ & $\underline{0,64}$ \\
\hline
\end{tabular}




\begin{tabular}{|c|c|c|c|c|c|c|c|}
\hline \multirow[b]{2}{*}{$\mathrm{o}$} & \multirow{2}{*}{$\begin{array}{c}\text { Kantor Urusan } \\
\text { Agama }\end{array}$} & \multirow[b]{2}{*}{ Jumlah } & \multirow{2}{*}{$\begin{array}{l}\text { Luas } \\
{[\mathrm{Ha}]}\end{array}$} & \multicolumn{2}{|c|}{ Sudah Sertifikat } & \multicolumn{2}{|c|}{ Belum Sertifikat } \\
\hline & & & & Jumlah & $\begin{array}{l}\text { Luas } \\
{[\mathrm{Ha}]}\end{array}$ & Jumlah & $\begin{array}{l}\text { Luas } \\
{[\mathrm{Ha}]}\end{array}$ \\
\hline & Bungursari & $\underline{206}$ & $\underline{13,43}$ & 203 & $\underline{13,37}$ & $\underline{3}$ & $\underline{0,06}$ \\
\hline & Jumlah & 1.679 & 81,20 & 1.533 & 72,74 & 146 & 8,46 \\
\hline
\end{tabular}

Sumber : Sistem Informasi Wakaf Kementerian Agama Kota Tasikmalaya

Berdasarkan pantauan Badan Wakaf Indonesia (BWI) Perwakilan Kota Tasikmalya, masih banyak tanah-tanah wakaf yang belum terdata dalam sistem ini. Termasuk wakaf yang sudah dibangun pondok Pesantren, Masjid maupun lainnya (M. Djayadi, 2016).

Dari semua data yang tersaji ini ada yang nazhir perseorangan ada juga yang nazhir badan hukum atau organisasi, walaupun hampir kebanyakan bernazhir perseorangan. Tidak dapat diketahui data konkret berapa jumlah tanah wakaf yang dialihkan kepada nazhir badan hukum. Namun banyak pengajuan penggantian nazhir wakaf pada tahun 2018 (M. Djayadi, 2016). Ada beberapa Kecamatan yang mengajukan perubahan nazhir wakaf dari nazhir perseorangan menjadi nazhir badan hukum. Diantara kecamatan itu adalah Kecamatan Tawang, Kecamatan Mangkubumi, Kecamatan Cihideung, Kecamatan Cipedes, dan Kecamatan Kawalu dengan jumlah lokasi sebagaimana dapat dilihat pada tabel 2.

Tabel 2. Jumlah Lokasi Tanah Wakaf yang berubah Status menjadi Nazhir Badan Hukum Tahun 2018

\begin{tabular}{|c|c|r|}
\hline o & Kantor Urusan Agama & Jumlah Lokasi \\
\hline$\cdot$ & Kawalu & 2 \\
\hline$\cdot$ & Cipedes & 6 \\
\hline$\cdot$ & Cihideung & 2 \\
\hline & Tawang & 3 \\
\hline
\end{tabular}




\begin{tabular}{|c|c|c|}
\hline o & Kantor Urusan Agama & Jumlah Lokasi \\
\hline$\cdot$ & Mangkubumi & 2 \\
\hline$\cdot$ & & \\
\hline & Jumlah & 15 \\
\hline
\end{tabular}

Sumber : Badan Wakaf Indonesia (BWI) Perwakilan Kota Tasikmalaya

Penggantian nazhir selama tahun 2018 memberikan indikator adanya kebutuhan nazhir selain perseorangan di masyarakat. Penggantian nazhir wakaf perseorangan ke badan hukum badan hukum di wilayah hukum BWI Kota Tasikmalaya terjadi di 5 (lima) Kecamatan tersebut di atas dan diajukan oleh beberapa badan hukum dianataranya (BWI Kota Tasikmalaya):

1. Ormas Muhammadiyah Kota Tasikmalaya

2. Perkumpulan Persatuan Islam (PERSIS) Kota Tasikmalaya

3. Yayasan Idrisiyyah Kabupaten Tasikmalaya

Dari ketiga badan hukum ini Persyarikatan Muhammadiyah merubah status nazhir wakaf sejumlah 13 Lokasi yaitu di Kecamatan Cipedes, Tawang, Mangkubumi, Cihideung, Kawalu. Sedangkan Perkumpulan Persatuan Islam (PERSIS) hanya 1 lokasi di Kecamatan Cipedes dan Yayasan Idrisiyyah Kabupaten Tasikmalaya 1 lokasi di Kecamatan Tawang. Untuk lebih jelasnya dapat dilihat pada tabel 3.

Tabel 3. Data Perubahan Status Nazhir Badan Hukum tahun 2018

\begin{tabular}{|c|c|c|c|c|c|}
\hline \multirow[b]{2}{*}{$\mathrm{O}$} & \multirow{2}{*}{$\begin{array}{c}\text { Kantor } \\
\text { Urusan Agama }\end{array}$} & \multirow{2}{*}{$\begin{array}{l}\text { Jumlah } \\
\text { Lokasi }\end{array}$} & \multicolumn{3}{|c|}{ Badan Hukum } \\
\hline & & & Muhammadiyah & PERSIS & $\begin{array}{l}\text { Yayasan } \\
\text { Idrisiyah }\end{array}$ \\
\hline & Kawalu & 2 & 2 & & \\
\hline & Cipedes & 6 & 5 & 1 & \\
\hline & Cihideung & 2 & 2 & & \\
\hline
\end{tabular}




\begin{tabular}{|l|r|r|r|r|r|}
\hline & \multirow{2}{*}{$\begin{array}{c}\text { Kantor } \\
\text { o }\end{array}$} & \multirow{2}{*}{$\begin{array}{l}\text { Jumlah } \\
\text { Urusan Agama }\end{array}$} & \multicolumn{3}{|c|}{ Lokasi } \\
\cline { 4 - 6 } & Tawang & 3 & 2 & & 1 \\
\hline$\cdot$ & Muhammadiyah & PERSIS & $\begin{array}{l}\text { Yayasan } \\
\text { Idrisiyah }\end{array}$ \\
\hline & Mangkubumi & 2 & 2 & & \\
\hline & Jumlah & 15 & 13 & 1 & 1 \\
\hline
\end{tabular}

Sumber : Badan Wakaf Indonesia (BWI) Perwakilan Kota Tasikmalaya

Pengajuan status perubahan nazhir dari perseorangan ke badan hukum ini, secara masif terjadi pada tahun 2018. Pengajuan tersebut dilakukan langsung oleh para pengurus masing-masing lembaga di tingkat Kota Tasikmalaya. Seperti perubahan status yang diajukan oleh Muhammadiyah diorganisir oleh PD Muhammadiyah Kota Tasikmalaya, demikian juga Perkumpulan Persatuan Islam (PERSIS) oleh PD PERSIS Kota Tasikmalaya, dan Yayasan Idrisiyah dilakukan oleh Pengurus Pusat Yayasan Idrisiyyah yang berada di wilayah Cisayong Kabupaten Tasikmalaya walaupun locus tanah wakafnya berada di Kota Tasikmalaya.

Penggantian nazhir wakaf PD Muhammadiyyah Kota Tasikmalaya, atas aset wakaf PDM didasarkan atas surat Instruksi Pimpinan Pusat Muhammadiyah untuk melaksanakan tanfidz keputusan Tanwir Muhammadiyah tahun 2012. Tujuan instruksi tersebut adalah untuk menertibkan tanah hak milik dan tanah wakaf persyarikatan yang masih atas nama perseorangan menjadi atas nama Persyarikatan. Instruksi dari Pimpinan Pusat Muhammadiyah dengan pertimbangan lebih maslahat Nadzir Persyarikatan (PP Muhammadiyah) daripada Nadzir perseorangan dan dalam perspektif maqasidus syariah termasuk hifz ad-dīn dan hifz al-māl (Arip Somantri, tt).

Tidak berbeda dengan pandangan PD Muhammadiyah Kota Tasikmalaya, perwakilan Yayasan Idrisiyyah pun menuturkan bahwa penggantian nazhir wakaf dari perseorangan ke yayasan Idrisiyyah adalah bertujuan untuk membereskan dan merapihkan administrasi wakaf sehingga semua sertifikat wakaf dapat disimpan di Kantor Pusat Yayasan Idrisiyyah, karena selama ini administrasi tersebut disimpan di zawiyah atau cabang Idrisiyyah. Ini merupakan instruksi langsung dari Kantor Yayasan Idrisiyyah Pusat supaya memiliki kemanfaatan dan kemaslahatan yang lebih jauh untuk umat Islam (Imam Muharram, $t \mathrm{t}$ ).

Ketua Bidang Garapan Perwakafan PD Persatuan Islam Kota Tasikmalaya yang menjelaskan bahwa selain merupakan instruksi dan amanat organisasi, penggantian nazhir wakaf dari perseorangan ke badan hukum memiliki nilai-nilai kemanfaatan dan kemaslahatan yang lebih besar. Termasuk dalam rangka penataan adiministrasi wakaf yang dimiliki oleh Persatuan Islam supaya dapat lebih baik. 


\section{Maslahah dalam Nazhir Badan Hukum}

Tujuan dari syariat Islam tersimpul dalam maqashid asy-Syari'ah yang lima termasuk dalam masalah perubahan status nazhir wakaf dari perseorangan ke badan hukum. Dari analisis al-usul al-khamsah atau al-usul al-syari'ah atau ad-daruriyyat al-khamsah penggantian nazhir ke badan hukum memiliki kemaslahatan dalam pencapaian maqashid asysyari'ah, yaitu: memelihara agama (ḥifụ al-dīn), memelihara jiwa (ḥifụ al-nafs), dan memelihara harta kekayaan (hị al-māl) yang dapat digunakan untuk menilai kemaslahatan pada penggantian nazhir wakaf dari perseorangan ke badan hukum.

1. Tercapainya Tujuan Wakaf sesuai Syariat (hifz ad-Din)

Penggantian nazhir wakaf ke badan hukum, maka akan lebih menjamin tercapainya tujuan wakaf dalam syariat Islam. Pengelolaan harta wakaf oleh badan hukum yang profesional lebih memberikan kemanfaatan dan kemaslahatan dibandingkan dengan nazhir wakaf perseorangan. Jika nazhir wakaf tidak profesional dan menyebabkan harta wakaf terbengkalai maka nazhir tersebut dapat dikategorikan kepada pengelola yang mencederai agama dalam hal ini hifz ad-din.

Wakaf merupakan salah satu bentuk amal jariyah yang memiliki peran sangat penting bagi pengembangan sosial, ekonomi, dan budaya dalam rangka untuk meningkatkan kesejahteraan masyarakat. Undang-undang Nomor 41 Tahun 2004 tentang wakaf yang mengatur tentang adanya nazhir badan hukum memberikan kesempatan kepada nazhir yang diberi amanah untuk mewujudkan ketertiban dan keteraturan dalam pengelolaan harta wakaf yang berimbas pada terpeliharanya prinsip-prinsip syari'at wakaf (hifz ad-Din).

Terkait pengelolaan harta wakaf ini, Umar ibn al-Khattab pernah meminta saran kepada Rasulullah SAW terkait harta wakaf berupa kebun, dalam hadits disebutkan sebagai berikut:

Sesungguhnya umar memiliki tanah di Khaibar, lalu dia datang kepada Nabi saw. untuk meminta arahan beliau dan berkata: 'Saya memiliki kebun (tanah) yang belum saya manfaatkan. Apa yang engkau sarankan kepadaku?' Nabi menjawab: 'Jika kau berkehendak, kau bisa menahan pokoknya dan menyedekahkan hasilnya.' Lantas Umar menyedekahkannya, tidak menjual pokoknya, tidak menghadiahkannya, dan tidak mewariskannya. Akan tetapi beliau menyedekahkannya untuk fakir miskin, kerabat, memerdekakan hamba sahaya, keperluan di jalan Allah, ibnu sabil, dan tamu. Tidak masalah juga jika orang yang mengelolanya mengambil hasilnya sewajarnya untuk keperluan nafkah tanpa bertujuan mengumpulkan harta (Muhammad bin Isma'il Al-Bukhari, $\mathrm{tt}$ )

Dari uraian hadits tersebut jelas nampak bahwa pengelolaan yang berimbas kepada kemanafaatan dan kemaslahatan lebih diutamakan. Menurut al-Gazâli bahwa setiap sesuatu yang dapat melindungi eksistensi salah satu dari kelima hal tersebut dikualifikasi sebagai mașlaḥah, tetapi setiap sesuatu yang dapat mengganggu dan mengabaikan salah satu dari kelima hal tersebut dinilai sebagai mafsadah serta menolak terhadap sesuatu yang mengabaikannya merupakan mașlaḥah (Abu Hamid al-Gazali, 1999). 


\section{Meningkatkan profesionalitas Person Nazhir (hifz an-Nafs)}

Pada dasarnya subjek hukum dalam hukum perdata adalah orang atau yang dikenal dengan persoon. Subjek hukum orang(persoon) tersebut dibagi menjadi dua bentuk yaitu pertama, naturalijk person (manusia pribadi) atau istilah lain subyek hukum dengan wujud fisik manusia dan kedua, rechtpersoon (Setiyono, 2005) (badan hukum) atau dikenal dengan (subyek hukum dengan wadah semu) (Windi Afdal, 2016). Dalam terminologi fiqih kontemporer istilah persoon disebut dengan syaksiyyah yang mencakup syakhsiyyah haqiqiyah maupun syaksiyyah i'tibariyah. Istilah sakhsiyyah haqiqiyah (naturalijk persoon) bila merujuk pada subyek hukum manusia, adapun yang dimaksud dengan syakhsiyyah i'tibariyah merupakan person selain manusia (recht persoon) (Imran Ahsan Khan Nyazee, 2016).

Fathurrahman Djamil, Guru Besar Fakultas Syariah UIN Syarif Hidyatullah Jakarta menyebutkan bahwa nazhir adalah pemimpin umum dalam wakaf. Dalm hal ini lembaga kenazhiran memiliki peran sentral dalam pengelolaan harta wakaf secara umum. Oleh karena itu eksistensi dan kualitas SDM nazhir harus betul-betul diutamakan dan menjadi prioritas utama dalam perwakafan.

Nazhir yang berupa badan hukum merupakan nafs juga dan memiliki kewenangan serta tanggung jawab yang sama di hadapan hukum. Jika ditinjau dari teori maṣlahah, adanya nazhir badan hukum tersebut mampu mewujudkan kemanfaatan (jalb al-manfa'ah) atau menghindari kemudaratan (daf'u al-madharrah).

Badan hukum tidak terbatas oleh waktu, jika person (nafs) meninggal maka tidak akan mempengaruhi kepada keberlangsungan pengelolaan harta wakaf, karena secara otomatis akan berganti kepada pengurus lainnya yang ditunjuk atau hasil musayawarah para pengurus badan hukum tersebut. Jadi dengan adanya penggantian nazhir perseorangan ke badan hukum memiliki kemaslahatan untuk memelihara dan menjaga jiwa atau person (hifz an-nafs).

3. Mengabadikan Manfaat Wakaf dan Meningkatkan Perekonomian (hifz al-mal).

Undang-undang Nomor 41 Tahun 2004 tentang Wakaf dibentuk untuk mengisi semangat pembukaan UUD 1945, yaitu memajukan kesejahteraan umum. Bahkan dalam UUD 1945 (bab XIV) terdapat bab khusus mengenai kesejahteraan sosial (sebelum amandemen), dan diubah menjadi perekonomian nasional dan kesejahteraan sosial yang terdiri atas dua pasal. Oleh karena itu, wakaf dalam dimensi wakaf produktif untuk mensejahterakan masyarakat tidak lepas dari konstitusi negara yang berlaku (Jaih Mubarak, 2009: 17-18).

Menurut sistem ekonomi Islam, wakaf memiliki tiga unsur penting dalam perekonomian yaitu: Pertama, Wakaf sebagai pengurang tingkat suku bunga (rate of interest) karena wakaf dapat mengurangi tingkat suku bunga secara nyata yaitu dengan menyediakan sarana publik yang diperlukan masyarakat tanpa membebankan biaya kepada pihak pemerintah. Kedua, Wakaf sebagai salah satu mekanisme redistribusi kekayaan (redistribution of wealth). Sistem wakaf mampu mengurangkan ketidakmerataan distribusi pendapatan dan 
kemiskinan. Ketiga Mekanisme wakaf mengandung unsur investasi dan tabungan (saving). Wakaf dari segi ekonomi merupakan tindakan yang menggabungkan antara investasi dan tabungan (saving). Ini karena wakaf sendiri adalah investasi, karena barang yang diwakafkan dapat menghasilkan manfaat dan faedah yang dibutuhkan masyarakat (Murtado Ridwan, 2012: 93-95).

Dengan penggantian nazhir wakaf dari perseorangan ke badan hukum, memberikan peluang yang sangat luas untuk memproduktifkan harta wakaf lebih optimal. Dalam kaca maqashid asy-Syariah jelas mengandung kemaslahatan. Sebagaimana dijelaskan oleh alGazâli bahwa setiap sesuatu yang dapat melindungi eksistensi hifdz al-mal dikualifikasi sebagai mașlaḥah, tetapi setiap sesuatu yang dapat mengganggu dan mengabaikandinilai sebagai mafsadah serta menolak terhadap sesuatu yang mengabaikannya merupakan maṣlaḥah ( Al-Ghazali: 287).

\section{SIMPULAN}

Nazhir memiliki peran sentral dan strategis dalam pengelolaan harta wakaf karena bertugas untuk mengelola harta wakaf dengan sebaik-baiknya. Dalam upaya untuk mengoptimalkan pengelolaan dan pendayagunaan harta wakaf, perundang-undangan dan regulasi perwakafan lainnya mengakui dan mengatur nazhir wakaf organisasi atau lembaga dan badan hukum, meskipun sebelumnya dalam kitab-kitab fikih nazhir semacam ini tidak dikenal.

Untuk mewujudkan tujuan wakaf secara syar'i, regulasi yang berisi pengakuan terhadap nazhir badan hukum ini sarat dengan nilai-nilai maqashid syari'ah. Demikian pula aturan dan persyaratan yang ditetapkan dalam undang-undang, peraturan pemerintah dan peraturan Badan Wakaf Indonesia pun tidak terlepas dari usaha untuk memenuhi maqashid syari'ah wakaf sendiri.

Dalam kasus penggantian nazhir wakaf dari perseorangan ke badan hukum di wilayah hukum Badan Wakaf Indonesia Perwakilan Tasikmalaya, tidak terlepas dari semangat untuk mewujudkan tujuan wakaf itu sendiri. Baik dari Muhammadiyah, PERSIS maupun yayasan Idrisiyyah mengacu kepada kemaslahatan umum yaitu penertiban aset wakaf yang dimilikinya dan berupaya untuk mengoptimalkan pengelolaan wakaf yang lebih baik lagi. Selain itu penggantian nazhir perseorangan kepada nazhir lembaga dirasa penting karena nazhir lembaga atau badan hukum akan mampu mengelola aset wakaf dengan lebih profesional.

Maslahah yang merupakan kaidah inti dari maqashid asy-syari'ah dapat dijadikan alasan penggantian nazhir wakaf ke badan hukum untuk mendongkrak profesonalisme pengelolaan harta wakaf menuju wakaf yang produktif. Dari analisis al-usul al-khamsah atau al-usul al-syari'ah atau ad-daruriyyat al-khamsah penggantian nazhir ke badan hukum memiliki kemaslahatan dalam pencapaian maqashid asy-syari'ah, yaitu: memelihara agama (ḥifẓ al-dīn), memelihara jiwa (ḥifẓ al-nafs), dan memelihara harta kekayaan (ḥifẓ al-māl). 


\section{REFERENSI}

Abadi, Muhammad ibn Ya'qub al-Fairuz. (t.th). Al-Qamus Al-Muhit, Bayrut: Dar al-Fikr.

Afdal, Windi. (2016). Korporasi Dalam Hukum Organisasi Bisnis Islam. Jurnal Hukum \& Pembangunan 47 No. 3 (2016): 233-22.

Al-Afriqi, Ibn Manzur. (t.th). Lisan al-'Arabi. Beirut: Dar al-Fikr.

Al-Bukhari, Muhammad ibn Isma'il. (1400). Shahih al-Bukhari. Kairo: Mathba'ah alSalafiyyah.

Al-Fasi, Allal. (1971). Maqâshid asy-Syarî‘ah wa Makarimuha. Mesir: Dar al-Ma’arif.

Al-Gazali, Abu Hamid. (1983). al-Mustashfa Min Ilm al-Usul. Beirut: Dar al-Kutub alIlmiyyah.

Al-Gazali, Abu Hamid. (1999). Syifa al-Galil fi Bayan ash-Shabah wa al-Mukhil wa Masalik al Talil. Beirut: Dar al-Kutub al-Ilmiyah.

Al-Juwaini, Al-Imam al-Haramain Abi al Maali Abd al Malik Ibn Abdullah Ibn Yusuf. (1400). al-Burhan Fi Usul al-Fiqh. Kairo: Dar al-Ansar.

Al-Munawwar, Said Agil Husin. (1998). Konsep al-Maslahah Sebagai Salah Satu Sumber Perundangan Islam. International Journal of IsIamic Studies Islamiyat, Malaysia: Fakulti Pengajian Islam Universiti Kebangsaan Malaysia. vol 18 \& 19.

An-Naisaburi, Muslim bin al-Hajjaj an-Naisaburi. (t.t). Shahih Muslim. t.tp: Thab'ah alTurkiyyah.

Asy-Syatibi, Abu Ishaq Ibrahim Ibn Musa al Lakhim al Garnatti. (t.t.). al-I'tisam. Makkah: alMaktabah al-Faisaliyyah.

Asy-Syatibi, Abu Ishaq Ibrahim Ibn Musa al Lakhim al Garnatti. (1975). al-Muwaffaqat Fi Usul asy-Syari'ah. Beirut: Dar al-Ma'rifah. 1975.

Crane, Robert Dickson. Compassionate Justice: Source of Convergence between Science and Religion Part 3. The American Muslim (TAM), http://theamericanmuslim.org/tam.php/tam/contact.

Direktorat Pengembangan Zakat dan wakaf. (2004). Paradigma Baru wakaf di Indonesia, Jakarta: Dirjen Bimas dan Peny Haji.

Erickelman, Dale F. (2000). Shatibi's Philosophy of Islamic Law by Muhammad Khalid. Journal of Law and Religion. Vol. 15, No. 1/2. 
Kasdi, Abdurrahman Kasdi. (2014). "Peran Nadzir Dalam Pengembangan Wakaf". ZISWAF: Jurnal Zakat dan Wakaf, Vol. 1, No. 2.

Makdisi, John. Hard Cases and Human Judgment In Islamic and Common Law. Journals IUPUI, https://journals.iupui.edu/index.php/iiclr/article/viewFile/17378/17507.

Muallim, Amir dan Yusdani. (1999). Konfigurasi Pemikiran Hukum Islam. Yogyakarta: UIIPress, 1999.

Ma'luf, Lois. (1987). al-Munjid fi al-Lugah wa al-A'lam. Beirut: Dar al-Masriq.

Munawwir, Ahmad Warson. (1984). Kamus al-Munawwir, Yogyakarta: Unit Pengadaan Buku Buku Ilmiah Ponpes Al-Munawwir.

Mubarok, Jaih. (2009). Wakaf Produktif. Bandung: Kanwil Departemen Agama Propinsi Junsurawa Barat.

Opwis, Felicitas. (2010). Mașlaha and the Purpose of the Law: Islamic Discourse on Legal Change from the 4th/10th to 8th/14th Century. Leiden • Boston: Brill.

Qaed, Issa and Elvan Syaputra. (2014). Maslahah as an Islamic Source and its Application in Financial Transactions. Journal of Research in Humanities and Social Science, Volume 2, Issue 5. pp: 66-71 lihat access at www.questjournals.org.

Praja, Juhaya S. (1995). Filsafat Hukm Islam. Bandung: LPPM-UNISBA.

Ridwan, Murtado. (2012). Nazhir Profesional Kunci Kesuksesan Wakaf Produktif. Jurnal Muqtasid, Volume 3 Nomor 1

Setiyono, H. (2005). Kejahatan Korporasi: Analisis Viktimologi dan Pertanggungjawaban Korporasi dalam Hukum Pidana Indonesia, Malang: Bayumedia Publishing.

Syarifuddin, Amir Syarifuddin. (2011). Usul Fiqh. Jakarta: Kencana.

Taufik, Fikfik. (2014). Perubahan Status dan Kedudukan Nazhir Menurut Fikih dan Perundangan serta Implikasinya terhadap Produktivitas Harta Wakaf di Persatuan Islam. Bandung: Thesis Master UIN Sunan Gunung Djati.

Tim Penulis BWI. (2018). Himpunan Peraturan Perundang-undangan tentang Wakaf, Jakarta: Badan Wakaf Indonesia.

Wehr, Hans. (1980). A Dictionary of Modern Written Arabic, J. Milton Cowan (Ed.) (London: Mac. Donald \& Evan Ltd.

Yasid, Abu. (2011). Mashlahah sebagai Tujuan Istinbath al-Ahkam (Kajian al-Qawa'id alUshuliyyah al-Tasyri'iyyah dalam Ilmu Ushul Fiqh). Makalah dalam acara Pelatihan 
Bahthul Masail dan Workshop Metode Istinbath Hukum, Kerjasama Ma'had Aly Situbondo dengan Fakultas Syari'ah IAIN Sunan Ampel Surabaya, di Ma'had Aly Situbondo pada tanggal 23 dan 24 Februari 2011. 